\title{
Respons Empat Varietas Gladiol (Gladiolus hybridus L.) Terhadap Perendaman Benziladenin dalam Meningkatkan Pertumbuhan Tunas dan Produksi Subang
}

Response of Four Gladiolus (Gladiolus hybridus L.) Varieties to The Application of Benzyladenine in Increasing The Growth of Shoot and Corm Production

\section{Tri Dewi Andalasari ${ }^{1}$, Yayuk Nurmiaty ${ }^{1}$, Yohannes C Ginting ${ }^{1}$, dan Yamatri Zahra $^{1}$}

Jurusan Agroteknologi Fakultas Pertanian Universitas Lampung

*E-mail : tridewiandalasari@ymail.com; yamatri.zahra@gmail.com

\begin{abstract}
Gladiolus is a potential ornamental plant to be widely developed because its high aesthetic value. Generally, gladiolus is propagated vegetatively by using tuber that called corm. There are some problems in gladiolus vegetative propagation, which is corm has a dormancy period and produces only one to two corms for each gladiolus plant. The effort that can be done to solve these problems is to provide benzyladenine to gladiolus corm. This study aims to determine the response of four varieties of gladiolus (Gladiolus hybridus L.) that soak to benzyladenine in increasing the growth of shoot and corm production. This research was conducted in Bandar Lampung in 2017. The treatment was designed factorially (4 $x$ 4) using Randomized Block Design. The first factor was the varieties of gladiolus ie Anisa, Clara, Nabila, and Nurlaela. The second factor was the 100 ppm concentration of benzyladenine in repeating ie first, second, third, and fourth soaking. Data analysis was tested by Least Significant Difference (LSD) test at 5\% level. The results showed that (1) from four gladiolus corm varieties, Nabila produced the highest number of shoots at 10,34 shoots, while the variety that produces the highest number of corm was Clara at 5,71 corms, (2) the benzyladenine that used up to four times for soaking the corm resulted the same response in increasing growth of shoot and corm production of four gladiolus varieties, (3) the response of each gladiolus varieties didn't depend on how many times that benzyladenine used to soak the corm in increasing the growth of shoot and corm production of four gladiolus varieties.
\end{abstract}

Keywords: benzyladenine, corm, gladiolus

Disubmit : 11 Agustus 2018; Diterima: 12 Oktober 2018; Disetujui : 04 Januari 2019;

\section{PENDAHULUAN}

Gladiol termasuk dalam keluarga Iridaceae berasal dari bahasa latin gladius, seperti bentuk daunnya yang berarti pedang kecil, berasal dari Afrika Selatan dan menyebar di Asia. Pada tahun 1730, gladiol mulai memasuki daratan Eropa dan berkembang di Belanda. Kelebihan bunga potong gladiol adalah kesegarannya dapat bertahan 5 sampai 10 hari, memiliki warna bunga yang beragam, dan dapat berbunga sepanjang tahun, sehingga gladiol sangat potensial untuk dibudidayakan. Badan Pusat Statistik (2016) menyatakan bahwa 
produksi bunga potong gladiol pada tahun 2012 sebanyak 3.417.580 tangkai, 2.581.063 tangkai pada tahun 2013, 1.884.719 tangkai pada tahun 2014, dan meningkat hingga 2.552.060 pada tahun 2015.

Tanaman gladiol dapat diperbanyak secara generatif maupun vegetatif. Perbanyakan gladiol secara vegetatif dilakukan dengan menggunakan subang, anak subang, subang belah, dan kultur jaringan. Kendala perbanyakan gladiol secara vegetatif adalah setiap tanaman gladiol hanya mampu menghasilkan satu subang per umbi panen dan memiliki masa dormansi yang berlangsung selama 3,5 - 5 bulan tergantung dari varietasnya (Andalasari, 2004). Dormansi adalah kondisi benih yang belum dapat berkecambah walaupun kondisi dalam dan luar sudah sesuai. Menurut Herlina D, (1991) dormansi pada subang gladiol disebabkan oleh pengaruh asam absisat (ABA). Oleh karena itu, diperlukan suatu teknik budidaya yang tepat guna mempercepat akhir masa dormansi dan meningkatkan jumlah tunas yang aktif pada subang gladiol yaitu dengan menggunakan teknik pemacuan pertumbuhan tunas pada umbi dengan zat pengatur tumbuh.

Zat pengatur tumbuh adalah senyawa organik bukan nutrisi yang dalam konsentrasi rendah dapat mendorong, menghambat atau secara kualitatif mengubah pertumbuhan dan perkembangan tanaman. Sitokinin adalah salah satu zat pengatur tumbuh (ZPT) yang digunakan untuk memacu pembentukan tunas pucuk dan mampu mematahkan masa dormansi serta memacu pertumbuhan embrio (Mahadi, 2011). Golongan sitokinin yang dapat ditambahkan pada tanaman adalah benziladenin, merupakan golongan sitokinin aktif yang bila diberikan pada tunas pucuk akan mendorong poliferasi tunas, yaitu keluarnya tunas lebih dari satu. Setelah ZPT diaplikasikan pada subang, maka akan terjadi keseimbangan hormonal, sehingga masa dormansi subang lebih cepat selesai yang ditandai dengan terbentuknya primordia akar dan tunas. Tunas yang muncul lebih dari satu akan meningkatkan produksi gladiol dan subang yang dapat digunakan untuk bahan tanam musim berikutnya.

Larutan benziladenin biasanya hanya digunakan satu kali untuk perendaman, sehingga untuk merendam subang gladiol dalam jumlah banyak diperlukan benziladenin yang lebih banyak pula dan hal tersebut akan meningkatkan biaya produksi. Salah satu cara yang dapat dilakukan untuk mengurangi biaya produksi tersebut adalah dengan menggunakan kembali larutan benziladenin yang telah digunakan untuk merendam subang. Kumar, Reddy and Chandrashekar, (2008) melaporkan bahwa perlakuan perendaman subang dengan benziladenin konsentrasi 100 ppm menghasilkan jumlah tunas tertinggi. Berdasarkan uraian di atas, maka dilakukanlah penelitian ini untuk meningkatkan pertumbuhan tunas dan produksi subang dengan menggunakan larutan benziladenin yang sama secara berulang untuk perendaman.

\section{METODE PENELITIAN}

Penelitian ini dilaksanakan di Bandar Lampung sejak bulan Oktober 2016 sampai Juli 2017. Alat yang digunakan pada penelitian ini adalah alat tanam dan alat tulis. Bahan yang digunakan pada penelitian ini adalah subang gladiol varietas Clara, Anisa, Nabila, dan Nurlaela, tanah, sekam, pupuk kandang, air, dan larutan benziladenin 100 ppm.

Perlakuan pada penelitian ini disusun secara faktorial (4 x 4) dengan 3 ulangan. Rancangan percobaan menggunakan rancangan acak kelompok (RAK). Faktor pertama adalah varietas gladiol dengan empat taraf yaitu Anisa (v1), Clara (v2), Nabila (v3), dan Nurlaela (v4) (Tabel 1). Faktor kedua adalah benziladenin 100 ppm yang digunakan berulang sebanyak empat kali untuk perendaman dengan empat taraf yaitu perendaman pertama (b1), perendaman kedua (b2), perendaman ketiga (b3), dan perendaman keempat (b4) (Tabel 2). Pengelompokan dilakukan berdasarkan bobot subang. 
Jurnal Penelitian Pertanian Terapan

Tabel 1. Pengelompokan bobot subang gladiol

\begin{tabular}{lcccccccc}
\hline \multirow{2}{*}{ Kelompok } & \multicolumn{2}{c}{ Anisa (v1) } & \multicolumn{2}{c}{ Clara (v2) } & \multicolumn{2}{c}{ Nabila (v3) } & \multicolumn{2}{c}{ Nurlaela (v4) } \\
\cline { 2 - 9 } & $\mathrm{D}(\mathrm{cm})$ & $\mathrm{B}(\mathrm{gr})$ & $\mathrm{D}(\mathrm{cm})$ & $\mathrm{B}(\mathrm{gr})$ & $\mathrm{D}(\mathrm{cm})$ & $\mathrm{B}(\mathrm{gr})$ & $\mathrm{D}(\mathrm{cm})$ & $\mathrm{B}(\mathrm{gr})$ \\
\hline Besar (I) & $5,2-5,6$ & $40,5-47$ & $4,2-4,4$ & $25,5-26,5$ & $4,4-4,7$ & $37,5-40$ & $4,2-4,5$ & $24,5-26,5$ \\
Sedang (III) & $4,1-5,4$ & $19,5-20$ & $3,6-3,9$ & $18-19,5$ & $4,1-4,3$ & $23-24$ & $3,9-4,4$ & $17,5-18,5$ \\
Kecil (V) & $3-3,8$ & $13-14,5$ & $2,9-3,5$ & $13-13,5$ & $2,3-3,6$ & $11,5-13$ & $2,8-3,7$ & $11,5-13,5$ \\
\hline
\end{tabular}

Keterangan:

$\mathrm{D}$ : diameter subang

B : bobot subang

Tabel 2. Kombinasi perlakuan varietas dan perendaman benziladenin

\begin{tabular}{lcccc}
\hline \multicolumn{1}{c}{ Perendaman } & \multicolumn{4}{c}{ Varietas } \\
\cline { 2 - 5 } Benziladenin 100 ppm & Anisa (v1) & Clara (v2) & Nabila (v3) & Nurlaela (v4) \\
\hline Pertama (b1) & v1b1 & v2b1 & v3b1 & v4b1 \\
Kedua (b2) & v1b2 & v2b2 & v3b2 & v4b2 \\
Ketiga (b3) & v1b3 & v2b3 & v3b3 & v4b3 \\
Keempat (b4) & v1b4 & v2b4 & v3b4 & v4b4 \\
\hline
\end{tabular}

Homogenitas keragaman diuji dengan uji Bartlett, aditivitas data diuji dengan uji Tukey. Data dianalisis dengan sidik ragam dan dilanjutkan dengan uji Beda Nyata Terkecil (BNT) pada taraf nyata 5\%.

Subang dibersihkan dari akar dan kulit pembungkus, lalu dimasukkan ke dalam wadah plastik yang telah berisi larutan benziladenin konsentrasi $100 \mathrm{ppm}$, ditutup rapat dan didiamkan selama 24 jam. Setelah 24 jam, subang ditiriskan dan diletakkan pada wadah plastik mika. Perendaman subang berikutnya menggunakan larutan benziladenin yang sama dan diulang hingga empat kali perendaman.

Media tanam menggunakan tanah, sekam, dan pupuk kandang dengan perbandingan 1:1:1, lalu diaduk hingga rata dan dimasukkan ke dalam polibag. Munculnya tunas lebih dari $1 \mathrm{~cm}$ pada subang menandai berakhirnya masa dormansi. Subang direndam dalam larutan Dithane-M45 untuk menghindari terserangnya penyakit, lalu ditanam dalam polibag sedalam $5 \mathrm{~cm}$. Penutupan subang dengan tanah dilakukan secara berkala disesuaikan dengan pertumbuhan tunas. Pemasangan ajir ketika tanaman berumur 2 minggu. Penyiraman media tanam ketika mulai mengering atau tidak turun hujan dengan air sebanyak $250 \mathrm{ml}$ untuk setiap polibag, pemupukan dengan pupuk NPK Mutiara ketika umur 20 dan 45 HST serta setelah panen bunga dengan dosis 5 gr per polibag untuk setiap kali pemupukan. Penyiangan gulma secara manual, pengendalian OPT dengan pestisida. Subang dipanen ketika kondisi tanaman sudah mengering. Variabel yang diamati yaitu mata tunas aktif, jumlah tunas, tinggi tanaman, jumlah daun, jumlah subang, diameter subang, bobot subang per tanaman, bobot rata - rata subang, dan bobot kering brangkasan.

\section{HASIL DAN PEMBAHASAN}

Hasil penelitian menunjukkan bahwa varietas Anisa, Clara, Nabila, dan Nurlaela memberikan respons yang baik terhadap benziladenin konsentrasi 100 ppm yang digunakan berulang sampai empat kali selama 24 jam. Seluruh varietas subang $100 \%$ bertunas di minggu kedua pada perendaman pertama, kedua, ketiga, dan keempat. Penelitian Nugroho, (2013) menunjukkan bahwa pemberian ZPT pada subang berumur 0 dan 2 MSP menghasilkan waktu lebih cepat 4 - 5 hari dalam menghasilkan tunas dibandingkan dengan pemberian ZPT pada subang berumur 4, 6, dan 8 MSP. Jika dibandingkan dengan hasil penelitian Nuryanti, (2012), subang berumur 3 bulan setelah panen yang diberi benziladenin konsentrasi $0,40,50$, dan $60 \mathrm{ppm}$ baru mulai bertunas pada minggu ke 7 dan bertunas $100 \%$ pada minggu ke 13. Penelitian tersebut sesuai dengan pendapat Sofiati, V., Andalasari, T. D., (2010) yang menyatakan bahwa pada fase juvenil tanggapan tanaman terhadap sitokinin akan tampak lebih cepat. Fase juvenil subang untuk dapat menerima rangsangan 
pertumbuhan dari luar diperkirakan pada awal pemanenan (0 - 2 MSP). Subang yang diuji dalam penelitian ini berumur 2 MSP dengan demikian hasil penelitian ini sesuai dengan pendapat Andalasari, (2010).

Tabel 3. Respons empat varietas gladiol terhadap perendaman benziladenin pada fase vegetatif tanaman

\begin{tabular}{|c|c|c|c|c|c|}
\hline Perlakuan & $\begin{array}{c}\text { Mata Tunas } \\
\text { Aktif }\end{array}$ & $\begin{array}{c}\text { Jumlah } \\
\text { Tunas } \\
\end{array}$ & $\begin{array}{c}\text { Tinggi } \\
\text { Tanaman }\end{array}$ & $\begin{array}{c}\text { Jumlah } \\
\text { Daun }\end{array}$ & $\begin{array}{c}\text { Bobot Kering } \\
\text { Brangkasan }\end{array}$ \\
\hline Varietas & .....tunas...... & .....tunas...... & $\ldots . . \mathrm{cm} . . .$. & ......helai...... & .....gram...... \\
\hline Anisa (v1) & $3,33^{c}$ & $7,37^{\mathrm{bc}}$ & $69,93^{b}$ & $7,94^{\mathrm{b}}$ & $6,00^{\mathrm{a}}$ \\
\hline Clara (v2) & $4,25^{\mathrm{b}}$ & $8,26^{\mathrm{b}}$ & $85,72^{\mathrm{a}}$ & $14,19^{\mathrm{a}}$ & $6,95^{\mathrm{a}}$ \\
\hline Nabila (v3) & $5,25^{\mathrm{a}}$ & $10,34^{\mathrm{a}}$ & $72,27^{\mathrm{b}}$ & $9,33^{\mathrm{b}}$ & $6,48^{\mathrm{a}}$ \\
\hline Nurlaela (v4) & $2,92^{c}$ & $5,82^{c}$ & $68,29^{\mathrm{b}}$ & $4,66^{\mathrm{c}}$ & $3,94^{\mathrm{b}}$ \\
\hline BNT $\alpha 0,05(30 ; 15)$ & 0,56 & 1,64 & 7,29 & 2,13 & 1,05 \\
\hline Benziladenin & .....tunas..... & .....tunas..... & .....cm...... & .....helai..... & .....gram..... \\
\hline Perendaman Pertama (b1) & $4,25^{\mathrm{a}}$ & $8,55^{\mathrm{a}}$ & $75,56^{\mathrm{a}}$ & $8,40^{\mathrm{a}}$ & $5,68^{\mathrm{a}}$ \\
\hline Perendaman Kedua (b2) & $4,00^{\mathrm{a}}$ & $8,32^{\mathrm{a}}$ & $74,07^{\mathrm{a}}$ & $8,76^{\mathrm{a}}$ & $5,93^{\mathrm{a}}$ \\
\hline Perendaman Ketiga (b3) & $3,83^{\mathrm{a}}$ & $7,44^{\mathrm{a}}$ & $77,57^{\mathrm{a}}$ & $9,33^{\mathrm{a}}$ & $5,72^{\mathrm{a}}$ \\
\hline Perendaman Keempat (b4) & $3,67^{\mathrm{a}}$ & $7,20^{\mathrm{a}}$ & $69,00^{\mathrm{a}}$ & $8,37^{\mathrm{a}}$ & $5,80^{\mathrm{a}}$ \\
\hline BNT $\alpha 0,05(30 ; 15)$ & 0,56 & 1,64 & 7,29 & 2,13 & 1,05 \\
\hline
\end{tabular}

Tabel 4. Respons empat varietas gladiol terhadap perendaman benziladenin pada fase generatif tanaman

\begin{tabular}{|c|c|c|c|c|}
\hline Perlakuan & Jumlah Subang & $\begin{array}{c}\text { Diameter } \\
\text { Subang }\end{array}$ & $\begin{array}{c}\text { Bobot Subang } \\
\text { per Tanaman }\end{array}$ & $\begin{array}{l}\text { Bobo Rata - } \\
\text { rata Subang }\end{array}$ \\
\hline Varietas & ......subang..... & .....cm..... & .....gram..... & .....gram..... \\
\hline Anisa (v1) & $3,70^{\mathrm{b}}$ & $2,92^{\mathrm{a}}$ & $30,72^{\mathrm{a}}$ & $9,28^{\mathrm{a}}$ \\
\hline Clara (v2) & $5,71^{\mathrm{a}}$ & $2,24^{\mathrm{b}}$ & $22,48^{\mathrm{ab}}$ & $4,58^{\mathrm{b}}$ \\
\hline Nabila (v3) & $4,23^{\mathrm{b}}$ & $2,62^{a b}$ & $28,46^{\mathrm{a}}$ & $7,30^{\mathrm{a}}$ \\
\hline Nurlaela (v4) & $1,98^{\mathrm{c}}$ & $2,92^{\mathrm{a}}$ & $14,07^{\mathrm{b}}$ & $8,71^{\mathrm{a}}$ \\
\hline BNT $\alpha 0,05(30 ; 15)$ & 1,09 & 0,40 & 9,55 & 2,92 \\
\hline Benziladenin & ......subang..... & .....cm...... & .....gram..... & .....gram...... \\
\hline Perendaman Pertama (b1) & $3,69^{\mathrm{a}}$ & $2,37^{\mathrm{a}}$ & $16,08^{\mathrm{a}}$ & $5,26^{\mathrm{a}}$ \\
\hline Perendaman Kedua (b2) & $3,91^{\mathrm{a}}$ & $2,80^{\mathrm{a}}$ & $26,50^{\mathrm{a}}$ & $8,06^{\mathrm{a}}$ \\
\hline Perendaman Ketiga (b3) & $4,19^{\mathrm{a}}$ & $2,73^{\mathrm{a}}$ & $26,50^{\mathrm{a}}$ & $7,72^{\mathrm{a}}$ \\
\hline Perendaman Keempat (b4) & $3,38^{\mathrm{a}}$ & $2,82^{\mathrm{a}}$ & $25,67^{\mathrm{a}}$ & $8,59^{\mathrm{a}}$ \\
\hline BNT $\alpha 0,05(30 ; 15)$ & 1,09 & 0,40 & 9,55 & 2,92 \\
\hline
\end{tabular}

Pada Tabel 3 dan 4 menunjukkan bahwa pertumbuhan vegetatif dan generatif gladiol pada penelitian ini dipengaruhi oleh perbedaan varietas yang digunakan tetapi tidak dipengaruhi oleh perendaman benziladenin konsentrasi 100 ppm yang dipakai secara berulang. Menurut Panjaitan, (2014) kinerja sitokinin eksogen dan endogen dapat mendukung pertumbuhan tunas tanaman. Benziladenin konsentrasi 100 ppm yang digunakan berulang sampai empat kali perendaman menghasilkan respons yang sama di seluruh variabel yaitu dapat meningkatkan pertumbuhan tunas dan produksi subang karena diduga tidak berubah konsentrasinya. Hasil penelitian ini mendukung penelitian Thohirah, A. L., Sa, F. C. L., (2010) yang menggunakan benziladenin konsentrasi 100 dan 150 ppm menghasilkan rimpang Curcuma alismatifolia bertunas 2 hari lebih cepat dibandingkan dengan rimpang tanpa perlakuan.

Varietas Clara menghasilkan bobot berangkasan tertinggi yaitu 6,95 g. Hal tersebut disebabkan varietas Clara juga menghasilkan jumlah tunas dan jumlah daun tertinggi dengan rata - rata 8,26 tunas dan 14,19 helai (Tabel 3). Menurut Andalasari, (2010) banyaknya tunas yang terbentuk akan meningkatkan jumlah daun yang pada akhirnya akan meningkatkan bobot berangkasan. Hasil penelitian andalasari 2010 menunjukkan bahwa varietas Clara menghasilkan jumlah tunas tertinggi kedua setelah varietas Kaifa yaitu 
dengan rata - rata sebanyak 3,94 tunas pada perendaman benziladenin konsentrasi $20 \mathrm{ppm}$. Benziladenin konsentrasi 100 ppm yang digunakan pada penelitian ini menghasilkan jumlah tunas yang lebih banyak dibandingkan dengan benziladenin konsentrasi 20 ppm.

Menurut Andalasari, (2010) respons varietas dipengaruhi oleh genetik yang dimunculkan pada bentuk dan morfologi subang. Subang varietas Clara lebih baik dalam penyerapan benziladenin karena memiliki permukaan tipis dan berlekuk. Diduga gladiol varietas Clara memiliki mutu yang baik diperkuat dari hasil penelitian Soedarjo, (2010), varietas Clara menghasilkan jumlah subang terbanyak jika dibandingkan dengan varietas Kaifa dan Nabila pada perlakuan kombinasi pupuk N dan K.

Setiap tunas yang terbentuk akan menjadi tanaman baru yang kemudian akan membentuk subang baru sesuai jumlah tunas (Sofiati, V., Andalasari, T. D., 2010). Semakin banyak subang yang dihasilkan maka diameter dan bobot rata - rata subang akan semakin kecil karena terjadi persaingan yang kuat untuk mendapatkan unsur hara, air, dan cahaya. Pada penelitian ini varietas Clara menghasilkan jumlah subang terbanyak tetapi diameter dan bobot rata - rata subangnya rendah. Menurut Badriah, D. S., Wuryaningsih, S., dan Rahayu, (2010) subang benih untuk produksi bunga gladiol minimal berdiameter 2,5 cm; subang varietas Clara belum memenuhi syarat menjadi subang benih produksi bunga.

\section{KESIMPULAN DAN SARAN}

Dari keempat varietas subang, varietas Nabila menghasilkan jumlah tunas terbanyak yaitu 10,34 tunas sedangkan varietas yang menghasilkan jumlah subang terbanyak adalah Clara yaitu 5,71 subang. Benziladenin yang digunakan empat kali untuk perendaman subang menghasilkan respons yang sama dalam meningkatkan pertumbuhan tunas dan produksi subang empat varietas gladiol. Respons masing - masing varietas gladiol tidak tergantung dari berapa kali benziladenin digunakan untuk merendam subang dalam meningkatkan pertumbuhan tunas dan produksi subang

Berdasarkan penelitian yang telah dilakukan maka disarankan untuk menggunakan kembali larutan benziladenin untuk perendaman lebih dari empat kali yang bertujuan untuk melihat sampai berapa kali benziladenin efektif digunakan.

\section{DAFTAR PUSTAKA}

Andalasari, T. D., Hendarto, K., dan F. (2004) 'Pengaruh Pemberian Kalsium Karbid (CaC2) terhadap Pematahan Dormansi Corm dan Pertumbuhan Dua Kultivar Gladiol (Gladiolus hybridus L.)', Jurnal Penelitian Pertanian Terapan, 4(2), pp. 1-5.

Andalasari, T. D (2010) 'Respon Pertumbuhan dan Produksi Bunga Gladiol (Gladiolus hybridus L.) terhadap Pembelahan Corm’, in Prosiding Seminar Nasional Sains Mipa dan Aplikasinya, pp. 215-219.

Andalasari, Tri Dewi (2010) 'Usaha Perbanyakan Subang Gladiol (Gladiolus hibridus L) dengan Menggunakan Benziladenin (BA)’, Jurnal Penelitian Pertanian Terapan, 11(1), pp. 45-51.

Badriah, D. S., Wuryaningsih, S., dan Rahayu, R. S. (2010) 'Pembentukan Varietas Gladiol yang Novel', J. Agrivigor, 10(1), pp. 84-98.

H Panjaitan, L., Ginting, J. and Haryati, H. (2014) 'Respons Pertumbuhan Berbagai Ukuran Diameter Batang Stek Bugenvil (Bougainvillea SpectabilisWilld.) Terhadap Pemberian Zat Pengatur Tumbuh', Jurnal Agroekoteknologi Universitas Sumatera Utara, 2(4), pp. 1384-1390.

Herlina D (1991) Gladiol. Jakarta: Swadaya.

Kumar, P., Reddy, Y. and Chandrashekar, R. (2008) 'Effect of growth regulators on flowering and corm production in gladiolus', Indian Journal of Horticulture, 65(1), pp. 73-78. 
Mahadi, I. (2011) 'Pematahan dormansi biji kenerak menggunakan hormon 2,4-d dan Bap secara mikroprapagasi.pdf - Unknown - Unknown.pdf'.

Nugroho, E. D. S. (2013) 'Percepatan Pematahan Dormansi Subang Gladiol (Gladiolus hybridus) dengan Aplikasi Zat Pengatur Tumbuh', Institut Pertanian Bogor.

Nuryanti, R. (2012) 'Respons Varietas Gladiol (Gladiolus hybridus L.) terhadap Pemberian Benziladenin (BA) pada Pertumbuhan Tunas dan Produksi Bibit Gladiol’.

Soedarjo, M. dan S. W. (2010) 'Respons Beberapa Varietas Nasional Gladiol Terhadap Pemupukan N Dan K', Jurnal Hortikultura, 20(2), pp. 148-156. doi: 10.21082/jhort.v20n2.2010.p.

Sofiati, V., Andalasari, T. D., and Y. (2010) 'Pengaruh Konsentrasi dan Lama Perendaman Kinetin Pada Perbanyakan Tunas dan Umbi Bibit Gladiol (Gladiolus hybridus)', Jurnal Agrotropika, 15(2).

Thohirah, A. L., Sa, F. C. L., dan K. (2010) 'Breaking Bud Dormancy and Different Shade Levels for Production of Pot and Cut Cucurma alismatifolia", American Journal of Agricultural and Biological Sciences, 5(3), pp. 385-388. 